Journal of Social and Development Sciences

Vol. 3, No. 10, pp. 342-349, Oct 2012 (ISSN 2221-1152)

\title{
Coping with Drought among the Communities Living in the Lake Victoria Basin of Kenya
}

\author{
J. K. Chumo1' D. K. Agui² \\ ${ }^{1}$ School of Science, Chepkoilel University College, Eldoret, Kenya \\ ${ }^{2}$ School of Education, Moi University, Eldoret, Kenya
}

\begin{abstract}
Drought is of great concern throughout the continent of Africa because of its devastating effects that it has inflicted on the economy of some of the countries. Drought has been recorded to be one of the most felt disasters in recent years in Kenya. The drought that affected Kenya in the year 2000 and 2010 was indeed remarkable in that the country resorted to loss of lives, loss of livestock, power rationing and drying of agricultural crops among other problems. This study developed a technique to depict spatially, the extent, relative severity and location of areas mostly affected by drought in the Lake Victoria basin of Kenya. This was done using the normalized difference vegetation index (NDVI) plots and maps developed using the Geographical Information System (GIS) software. The indices were generated using the C++ program. NDVI indices revealed that most parts of the basin were moderately dry throughout the year. The study investigated the impacts of drought in the area by use of questionnaires and interviews. The impacts identified were mainly crop failure, depletion of water resources and lack of pasture for livestock. The complex and multidimensional nature of drought requires a long term, well-organized and coordinated research plan and action involving all the stakeholders. This study summarized coping strategies adopted by the communities living within the Lake Victoria basin to mitigate drought phenomenon. Some of the strategies include; planting of drought resistant crops, food storage sharing and purchasing of food among others. Recommendations have been suggested for policy makers, planners and agriculturalists to implement to improve agricultural output in a drought prone area like the Lake Victoria Basin of Kenya. In particular, the study highly recommends development of a comprehensive drought policy to be implemented in managing drought in Kenya.
\end{abstract}

Keywords: Lake Victoria Basin, Drought impacts, Normalized difference Vegetation index, Drought coping strategies, Drought severity

\section{Introduction}

The study area lies between longitudes $34^{\circ} \mathrm{E}$ and $35^{\circ} \mathrm{E}$ and latitudes $1^{\circ} 30^{\prime} \mathrm{S}$ and $1^{\circ} 20^{\prime} \mathrm{N}$. This area often experiences some of the harshest drought conditions similar to other areas in Kenya commonly referred to as arid and semi-arid lands. The climate of the area is influenced very much by the lake. According to Koppen's classification, the climate in the area is sub-humid tropical savannah (Sombroek, 1982). The rainfall in the area is about $750 \mathrm{~mm}$ per annum, three quarters of which is received in March to April and its distribution is highly affected by the topography. Temperatures on the eastern shores reach maximums of between 29 and $30^{\circ} \mathrm{C}$ (WMO, 1982). The annual humidity ranges between $61-89 \%$ in the morning hours and $44-74 \%$ in the afternoon (Agwata, 1992). According to Nyenze (1980) the areas around the lake experiences, actual annual evaporation $\left(E_{0}\right)$ values greater than $1000 \mathrm{~mm}$ and monthly values range between 100 and $170 \mathrm{~mm}$. The geology of the study area consists of rocks of Nyanzian age (Precambrian) and the recent deposits. The alluvial deposits and lacustrive sediments are mainly found along the shores of the Lake. Deep clay soils occur when the water movement is rather gentle, but more sandy soils are found on positions which are exposed to the wind and which have a strong water movement. The vegetation in the area of study can be described as bushed grasslands. The major land use is farming of beans, sorghum, rice, sugarcane, citrus fruits, tomatoes and cabbages, among others.

\section{Coping with Drought}

It is certain that the causes and occurrences of drought is outside the control of human beings. Since this phenomenon has a great impact on the people living in the area, there arises the need to tame it in such a way that its impacts are cushioned. During the 2009-2011 drought that hit various parts of Kenya, many parts 
were heavily affected including the Lake Victoria basin. Turkana County for instance was seriously affected with statistics indicating that over $25 \%$ of the livestock died. Experts blamed lack of early warning systems for the deaths, which wiped out the residents only means of livelihood. Mbithi and Wisner (1972) advanced the idea that in adjustment to drought, behaviors traits to total social systems change under extreme environmental calamities. They carried out a study on the impacts of drought in Eastern and Central Kenya and among the adjustments they enumerated were praying for the rainmakers to bring rain, praying, performing rites, planting early, seeking alternative sources of income by and using alternative food such as bush foods. Relief food dispensation is a commonly used strategy. This strategy, although quite widely used, has received a lot of criticism. Mbithi and Wisner (1972), in their paper noted that some of the disadvantages of relief food include difficulty in selection of needy families, misuse of the relief food and the inappropriate method of distribution. Prah (1978) states that problems brought by drought compel the society to develop palliative measures such as food storage devices. Beach (1977) further gave an example noting that the precolonial Shona of Botswana would counter the effects of drought on agriculture by cultivating more drought resistant ball brush millet instead of finger millet or they planted second crop hoping that this would be successful. The Sarua of the Kalahari responded by remaining socially mobile and fragmented into small groups. Cultural adaptation involved dietary habits which included consumption of species providing both food and water and it is also noted that the community got about $90 \%$ of its water from the plants (Devitt, 1977). Fleuret (1986) conducted a detailed study on the responses of the indigenous Taita during drought periods. Some of the responses he observed included adjusting farming systems, application of complex and integrated systems of exchange to bridge food shortages, dietary diversity, and dietary change. Other strategies applied in various African societies include; substitution of less desirable food for more palatable ones and increase in hunting and foraging activities during droughts (Cashdan, 1985).

Agricultural innovation is another response that has grown in popularity all over the world. One common practice in this case is the planting of drought resistant crops such as cassava, raw banana and maize varieties. Pastoralists redistribute their assets among Kinsfolk in areas less severely affected by drought (DenHartog, 1981). This is seen in the Luo of Kenya who mobilize relational networks e.g. through marriage to gain access to food surpluses in areas within 40-50 km (Cohen, 1983). Downing et al. (1989) summarized coping strategies with respect to subsistence production as soil conservation, water conservation and irrigation, inter or relay cropping, dispersed grazing, food shortage, sharing, and purchases of food. The last option was employed by seeking cash through selling of animals, seeking employment, selling of possessions and procurement of loans. The indigenous drought response mechanisms mentioned above have broken down because of social and economic change. Knowledge of wild and famine foods is disappearing, food preservation techniques have been abandoned, and hunting, foraging and pastoral dispersal restricted. Such mechanisms are essential for coping with natural disasters. In light of the above review, it can be seen that most of the quantitative analyses have been national or regional with little if any attention is being paid to drought "pockets" such as the study area. It is interesting to geographical or specific edaphic factors. Seasonal droughts, simple as they may appear have significance, therefore, analysis of drought on shorter scales (e.g. months) are of importance. Finally, integration of geographical modeling of drought and incorporation of social aspects and particularly from the affected population has not been evident in the review.

\section{Methodology}

NDVI Data: The collection of NDVI data commenced by identification of meteorological stations in the study area whose data were suitable for the analysis. For the stations accepted for this study, NDVI data was obtained from the Department of Resource Surveys and Remote Sensing (DRSRS), whose mandate is to collect the geospatial data/ information o most natural resources in Kenya, with a view to monitoring changes over time and space.

Data and drought impacts: Data on drought impacts were collected by use of interview schedules and documentary sources from the Ministry of agriculture. Methods of random sampling were used to select families for interviewing. In particular, cluster random sampling was employed in which the respondents were selected randomly in the selected sub basin region. For every sampling point/station selected, at least three interviews were conducted in order to cater for inaccurate information given by any of the interviewees. Approximately 300 respondents were interviewed and this was restricted to ages of 45 years 
and above to increase the accuracy of response on past events. The respondents included villagers and leaders (for example chiefs and head teachers). Data obtained from the villagers included variation in quantity of water used during drought and normal seasons, variations in crop yields, and the special attempts made to curb the problems encountered during droughts. Information acquired from respondents included the problems faced during drought periods and the mitigation measures Documentary information was obtained from the Ministry of Agriculture in form of yields obtained in each division for the past six years.

Other Data: To aid studying drought impacts and the extent in the area, several maps were required. These were land use map, population distributional map, rainfall distribution map and soil map. These maps were developed from existing maps. Normalized Difference Vegetation Index (NDVI) plots were also obtained. Use was made of ARC/INFO software, which is a computer package that converts maps into digital format and used for general map manipulation and algebra.

\section{Results and Discussion}

Spatial Analysis by use of normalized difference vegetation index (NDVI) plots: These maps show vegetation indices composited over 10 day's durations. The vegetation index is directly affected by climatic factors such as rainfall since it measures the amount of green matter in the vegetation. It was further applied to isolate the areas that were consistently showing low vegetation index values less than 0.15 , such areas being considered drought areas. The plots could also show the change in vegetation cover in similar months of different years and this was taken to represent the variation in rainfall availability. The NDVI plots were traced out for the desired periods and a suitable cut off threshold value were then traced out and marked. By visual interpretation, the dry areas were isolated and the changes in vegetation cover noted. Numerical values of NDVI (Table1) were obtained using the following equation.

$$
\mathrm{NDVI}=\frac{\left(c h_{2}-c h_{1}\right)}{c h_{2}+c h_{1}}
$$

Where $\mathrm{ch}_{1}$ and $\mathrm{ch}_{2}$ are data from NOAA-AVHRR (Advanced Very High Resolution Radiometer) Channels 1 and 2 with;

$$
\begin{aligned}
& \mathrm{ch}_{1}-\text { Visible band }(0.58-0.68 \mathrm{Um}) \\
& \mathrm{ch}_{2} \text { - Near infrared band }(0.73-1.10 \mathrm{Um})
\end{aligned}
$$

Spatial analysis using NDVI: Another analysis carried out on the spatial extents of drought was with respect to vegetation. There has been found to be a direct relation between the vegetation indices and rainfall variability (Hellden and Eklundh, 1988). Maps prepared from normalized difference vegetation index (NDVI) are shown in fig.1. The maps indicate the regions, which exhibit low vegetation, cover and these can be taken to represent the drought areas in the study region. These areas are seen to fall inside those already marked out above hence further supporting them as drought areas. Unfortunately, the NDVI data were only available for three years hence it was not possible to do any further temporal analysis. The above criteria defined the drought prone areas specifically in the Lakeshore catchments of the Lake Victoria Basin. Green vegetation is highly affected by climatic factors (rainfall and evapotranspiration) and hence can be a good indication of drought severity. The data was derived from satellite images (resolution of $1.1 \mathrm{~km}$ ).

Table 1: Mean monthly NDVI for the five meteorological stations studied

\begin{tabular}{llllll}
\hline Month & Kisumu airport & Kibos & Rusinga island & Kadenge & Muhuru bay \\
\hline January & 0.494 & 0.549 & 0.504 & 0.594 & 0.560 \\
February & 0515 & 0.525 & 0.490 & 0.530 & 0.534 \\
March & 0.543 & 0.560 & 0.502 & 0.571 & .0573 \\
April & 0.496 & 0.552 & 0.533 & 0.584 & 0.556 \\
May & 0.533 & 0.650 & 0.603 & 0.658 & 0.637 \\
June & 0.464 & 0.578 & 0.558 & 0.628 & 0.573 \\
July & 0.363 & 0.535 & 0.580 & 0.535 & 0.639 \\
August & 0.265 & 0.337 & 0.331 & 0.178 & 0.412 \\
September & 0.273 & 0.460 & 0.476 & 0.504 & 0.486 \\
October & 0.398 & 0.533 & 0.566 & 0.555 & 0.504 \\
\hline
\end{tabular}




\begin{tabular}{llllll}
\hline November & 0.419 & 0.505 & 0.463 & 0.618 & 0.543 \\
December & 0.504 & 0.559 & 0.453 & 0.629 & 0.579 \\
\hline
\end{tabular}

There are three distinct seasons in a year in the area studied, described by the rainfall patterns. These are the dry season (January to March), long rains season (April to September) and the short rains season (October to December). PET values calculated corroborate this, showing January to March having the highest PET values and least in the long rains season (Chumo, 2011).

Figure 1: Drought severity map based on NDVI index

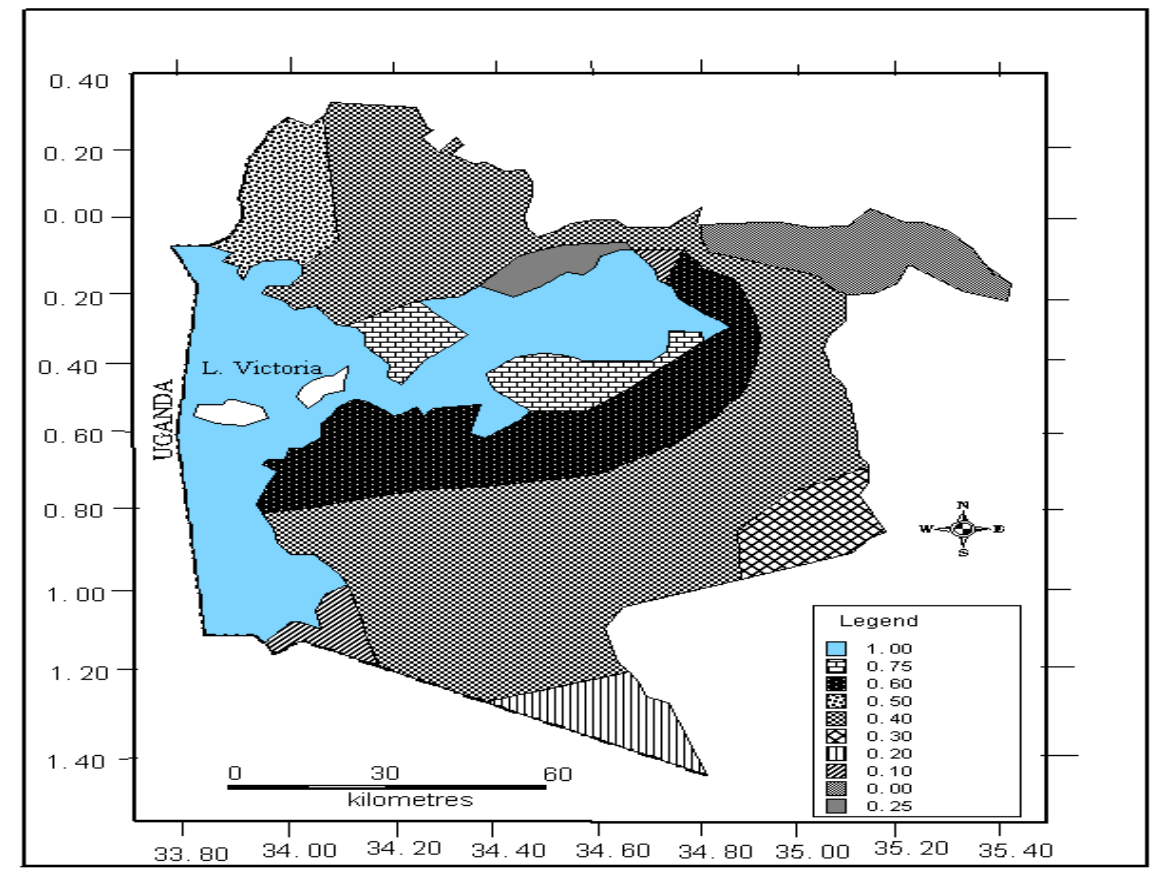

With respect to annual rainfall, rainfall variability and soils, it can be said that the drought assistance programs intended for this region should consider these areas on a priority basis. The areas have a strong combination of low rainfall, unsuitable soils and high rainfall variability.

Drought Impacts: The next important element investigated by the researcher was the impact of drought in the community. As was expected, the three major impacts identified were crop failure, depletion of water resources and lack of pasture for livestock. From the survey, the residents stated that most parts had soils suitable for agriculture but lacked adequate and reliable rainfall. The timing of rainfall, as explained by the respondents was that in many years it was too early, too late or inadequate. This puts farmers in a situation of uncertainty, which can easily lead to crop failure. An index was formulated to study the trend of the impact on water and agriculture. The ratio of water used by residents during normal seasons and during drought periods was taken as an index for water and the ratio of crop yields during normal and drought seasons used as an index for impact on agriculture. These indices are shown in table 2.

Table 2: Indices showing the impact of drought on water and agriculture

\begin{tabular}{ll}
\hline Index & Number of stations \\
\hline Index & station \\
$>5$ & 19 \\
$4-5$ & 4 \\
$3-4$ & 10 \\
$2-3$ & 6 \\
$1-2$ & 6 \\
\hline
\end{tabular}


Impacts on water resources: The trend of impacts on water resources was observed to be the most serious especially in the areas that were far from the lake and the perennial rivers. It was noted that in many areas, even slight reduction in precipitation it interfered with small rivers and streams that necessitated trekking in search of water. This impact was even more serious during major droughts that even big rivers experienced very low flow or at times dried up. Another area in which drought impacts were felt is with livestock farming. In areas, which experienced extreme dry conditions, the respondents stated that there was a problem with pasture even in slightly dry periods. The situation is even worse during drought and some extreme cases resulted in death of livestock. The interview schedules attempted to measure and compare the impacts of drought in different parts of the basin. This was measured by use of available water and the crop yields. Although the indices above owe every bit of their accuracy to the respondents, they can be used to approximate the nature of the drought impact on the study region. Most of the stations in the region can be clearly seen to be experiencing severe drought conditions as this is indicated by both criteria. These sampling stations, if compared to the results based on rainfall analysis indicate almost the same area and the drought vulnerability is seen to increase towards the lake. While examining the water sources of the residents of this region, the results of the finding on various sources of water is shown in table 3.

Table 3: Sources of water for the residents

\begin{tabular}{ll}
\hline Source & No. of respondents \\
\hline river & 40 \\
lake & 22 \\
rainwater & 27 \\
springs & 19 \\
ponds & 21 \\
boreholes & 10 \\
Tapped water & 17 \\
\hline
\end{tabular}

From the results, it can be stated that the majority of the residents in the area rely on rivers for water supply and the least used source of water are the boreholes. This implies that in drought season, rivers and streams end up drying and this would have a lot of impact on the residents. The areas of great concern in respect to water supply are those, which receive inadequate rainfall such that water storage systems have very low reliability and at the same time, they are too far from the lake and therefore they cannot utilize the water. The issue of water supply is very closely intertwined with economic status. This is because either the poor people are not able to construct water storage facilities, which would last in a dry season, or a drought period and they are therefore more vulnerable to rainfall variability. Most respondents who did not have water storage devices blamed it on the lack of adequate funds to construct them. Therefore, it is confirmed that drought impacts are pegged to the income levels of the residents. With reduced quantities of water inevitably, the trend of water consumption has to change. This involves changing the manner in which water is used and the quantities used. The survey revealed the trend of restriction of water use as shown in table 4.

Table 4: Restricted water uses during drought periods

\begin{tabular}{ll}
\hline Restricted uses & Respondents \\
\hline Cooking & 3 \\
Washing utensils & 10 \\
bathing & 39 \\
Washing clothes & 36 \\
drinking & 3 \\
Cleaning house & 30 \\
Total & 121 \\
\hline
\end{tabular}

Impact on agriculture: Agriculture records showing production of maize obtained for the years 1990 to 1995 are shown in table 5. 
Table 5: Agricultural records showing maize production between 1990 and 1995 in some divisions of Lake Victoria Basin

\begin{tabular}{llllllll}
\hline DIVISION & & & & YEARS & & \\
& $\mathbf{1 9 9 0}$ & $\mathbf{1 9 9 1}$ & $\mathbf{1 9 9 2}$ & $\mathbf{1 9 9 3}$ & $\mathbf{1 9 9 4}$ & $\mathbf{1 9 9 5}$ & MEAN \\
\hline Kabondo & 11 & 12 & 10 & 3 & 20 & 20 & 14.7 \\
Kasipul & 19 & 18 & 16 & 2 & 18 & 15 & 20.6 \\
E.Karachuonyo & 21 & 18 & 20 & 12 & 25 & 28 & 18.0 \\
Asego & 25 & 18 & 18 & 14 & 12 & 10 & 18.0 \\
Rangwe & 14 & 12 & 24 & 2 & 30 & 26 & 17.8 \\
Usigu & 19 & 17 & 18 & 14 & 24 & 15 & 10.5 \\
Rarieda & 9 & 10 & 10 & 15 & 10 & 9 & 11.8 \\
Bondo & 14 & 12 & 12 & 7 & 30 & 8 & 13.8 \\
Boro & 11 & 12 & 9 & 10 & 20 & 10 & 12.0 \\
Maseno & 20 & 18 & 20 & 15 & 30 & 24 & 21.2 \\
L.Nyakach & & & & & 20 & 9 & 9.83 \\
Muhoroni & 20 & 18 & 16 & 15 & 20 & 18 & 17.8 \\
Nyando & 20 & 12 & 10 & 7 & 10 & 5 & 10.7 \\
Winam & 13 & 14 & 14 & 8 & 17 & 23 & 14.8 \\
Mbita & 14 & 15 & 20 & 4 & 20 & 18 & 15.2 \\
Nyarongi & 18 & 20 & 20 & 2 & 12 & 15 & 14.5 \\
W.Karachuonyo & 11 & 12 & 10 & 3 & 20 & 20 & 12.7 \\
Mean & 15.7 & 14.6 & 15.0 & 8.94 & 19.9 & 15.8 & \\
\hline
\end{tabular}

Because of poor productivity, the residents have reduced agricultural activities in many areas including Rusinga Island, Muhuru bay, Kadenge and adjacent area among others. This was evident during field study where several areas were seen uncultivated even at a time when rains were expected. This can be attributed to demoralizing past experiences of crop failure. The result of this is that agricultural production is low and only available to those who manage to get a harvest. Those with financial capability resort to buying food but this is almost completely out of reach to the poor. Worse still, the poor sell the food they get during the harvesting season to supplement their income. This results in a vicious cycle of poverty. Drought therefore has great impacts on agriculture and generally on the lives of the affected (Olwero, 1998). Most affected farmers due to the lack of livelihoods and fodder availability are forced to migrate to towns in search of work and also in industrial sectors, while others migrate to neighboring counties to seek for employment in tea and sugarcane plantations.

Coping with Drought: The general area of study is a high farming potential area. Although drought is prone, they are of lower magnitude compared to those experienced in other parts of Kenya such as the northern and eastern regions. The management strategies are therefore not well developed here (Olwero, 1998). The following are some of the strategies employed by the residents in the study area are:

- Planting of drought resistant crops: These include both the indigenous crops such as cassava and new breeds such as seredo sorghum, hybrid maize and others. These require very little water to mature and they mature in shorter periods hence are suitable for this region. Cassava is very widely grown and serves as both subsistence and cash crop.

- Planting near riverbanks and lakeshores: This is applied both in very dry periods and in drought. Although major droughts also affect rivers, there is relatively high moisture near the riverbanks, which supply adequate moisture at least for hardy crops. This is however only applicable to the people who live near rivers.

- Storage of crops for use in dry years: This was seen only to work well if there is early warning of dry periods. The common practice noticed is string of grains in granaries used depending on the prospects of the season. This is however of very little practicability to the poor.

- Use of alternative pasture: Depending on the drought severities, cattle are moved as far as $20 \mathrm{~km}$ away during drought period. Most residents pointed out that they camp with their cattle in areas, 
which are less affected by the drought, often with relatives to join other herds until it rains. The problem noticed with this strategy is that there is a rapid spread of cattle diseases.

- Barter: Residents move too far off areas such as the Kisii and Nandi highlands and exchange their products such as reed baskets, lime etc for food. This happens mainly with the poor residents who cannot get money for buying food

\section{Conclusion and Recommendations}

Currently, Kenya is spending a huge sum of its GDP to control the adverse impact of climate change, which is rather disastrous to a developing nation. The current impetus to industrialize the country by the year 2030 is faced by challenges such as deforestation and consumption of natural resources that is likely to make the situation much worse in the coming years. Furthermore and of great interest, drought affects agricultural production and water resources. The variability in timing the amount of rainfall makes it very difficult for farmers to carry out agricultural activities effectively. Rainfall sets in late and at times ends early so that crops do not have enough water and these results in poor harvest and leads to famine. The results of the survey shows that residents largely depend on river water therefore drought adversely affect their source of water supply. This is more critical especially where water storage facilities are not available. Drought and health were also identified to be inextricably intertwined because of the relation between water quality and drought. With the foregoing results and conclusions, the study suggests various recommendations for action. Having identified drought in the study area as a serious problem affecting the residents, it is deemed fit more priority action to be undertaken. These actions are not recommended to be only in form of material aid per se but in the sense that the residents need to be more educated on how to cope with the harsh environment, to initiate different methods and activities which could enhance their survival. Use of appropriate crops that can stand drought cannot be overemphasized. Although some people were found to be using these, a great number of residents have not fully used them because of either non-availability or lack of appropriate awareness. It is essential to subsidize the cost of such seeds so that residents in most of these parts can easily obtain them. There is also need by the government to build seed banks of alternative crops that will minimize and cushion the adverse impact of rainfall shortage. It is also recommended that irrigation projects be stepped up especially with respect to areas identified in this study. Such projects could be made small scale for ease of cost management. Construction of dams along rivers drainage will serve as both supply of water for use and for increasing gravity on irrigation systems. In areas close to the lake, pumping of lake water to the higher parts and supplying by gravity fed can also help in agricultural production. One major problem that has been noted with pumping systems is maintenance (Olwero, 1998).

Most of these pumping systems require rehabilitation. There is need for special attention for this because in some areas, piped water systems and lift pumps were available but were all broken down. The construction of dams and irrigation systems should be undertaken along with the revival and strengthening of traditional knowledge in water harvesting and conservation. Drought prone communities, villages and areas to adopt and sustain drought-proofing methodologies. The lake basin development authority in its development plan for the whole basin have recommended a private wells assistance program, expansion and rehabilitation of existing systems and expansion of irrigation projects. These complement well with recommendations of this study. The early warning systems may be developed, which may sense the signs of an impending drought in the area of study. This monitoring system will be expected to collect and disseminate data, hence improve response to drought in this drought prone area. This system may utilize the capability of remote sensing and GIS technology. It is recommended that simple and easy to use water pumps be encouraged to be used in the area in order to improve water supply since they do not suffer adverse problems of maintenance. In all, development of such community projects requires active participation of the community members if they are to succeed. This is because the water supply systems would be used by the community and therefore they need to participate in the installation and taking care of them. There is urgent need by the government of Kenya to develop a well-defined drought policy to articulate and present comprehensive efforts to cope and mitigate drought in the country. The lack of this policy has shown that major undoing in the efforts of reducing the effects of drought is experienced in drought years of 1984, 1994 and 2010. 


\section{References}

Agwata, J. F. M. (1992). The response to Lake Victoria levels to regional and global climate. M. Phil Thesis, Moi university library, Kenya.

Beach, D. (1977). The Shona Economy. In the Roots of Rural Poverty in Central and Southern Africa, N. Parsons and R. Palmer, London.

Cashdan, S. (1985). Coping with risk: reprocity among the Basarwa of northern Botswana man (NS) 20.

Chumo, J. K. (2011). Spatial variability of droughts, a study of the Lake Victoria basin of Kenya.VDM publishing house ltd, Mauritius.

Cohen, D. (1983). Food production and Food Exchange in the pre-colonial Lakes Plateau Region. In: Imperialism, colonialism and Hunger; East and central Africa (Ed R. Rotberg) D.C.Health and CO. Lexington, MA.

Den-Hartog, A. (1981). Adjustment of Food behavior During Famine. In: Famine, Its causes .Effects and management. (Ed J. Robson)Gordon and Breach, N.Y.

Devitt, P. (1977). Coping with Drought in the Kalahari 'In: Drought in Africa 11, R.J.Harrison Church, D. Dalby and F. Bezzaz (Eds).

Downing, T. E. K., Gitu, K. \& Kamau, C. (1989). Coping with Drought in Kenya: National and local strategies. Lynne Reinner, Boulder.

Fleuret, A. (1986). Indigenous Responses to Drought in sub Saharan Africa. Disasters, 10(3).

Hell-den, U. \& Elkundh, L. (1988). National Drought Impact Monitoring A NOAA NDVI and precipitation Data study of Ethiopia. Lund University Press.

Mbithi, P. M. \& Wisner, B. (1972). Drought and Famine in Kenya: Magnitude and Attempted Solutions. Working paper No 46 Institute of Development Studies, University of Nairobi.

Nyenze, K. (1980). The Distribution of Actual Evaporation - Evapotranspiration over East Africa. Kenya Meteorological Department Research Report No. 7 Nairobi, Kenya.

Olwero, J. G. N. (1998). Some aspects of drought in the lake Victoria basin of Kenya. M Phil Thesis, Moi university library, Kenya.

Prah, K. K. (1978). Some Sociological Aspects of Droughts. In: Proceedings of the symposium on Drought in Botswana. National Museum Gaborone, Botswana. June 5 -8/78.

Rossi, G. M., Tsakiris, T. \& Giakoumarks, S. (1992). On Regional Drought Estimation and Analysis. Water Resources Management, 6, 249-277.

Sombroek, W. G., Baun, H. M. \& Van-der, P. (1982). Exploratory soil map and Agro-climatic zone map of Kenya. 